This is an Accepted Manuscript of an article published by Taylor \& Francis in International Journal of Geotechnical Engineering on 01/02/19, available online: https://www.tandfonline.com/doi/ abs/10.1080/19386362.2019.1573475?journalCode=yjge20 


\section{Three dimensional finite element analyses of ground settlement and structural damage caused by irrigation of desert landscapes overlying collapsible soil strata}

Ramesh Vandanapu (Corresponding author)

PhD Student, School of Engineering and the Environment, Kingston University London, UK K1452539@kingston.ac.uk, Tel: +971559434709

Assistant Professor in Civil Engineering, Amity University, Dubai, U.A.E

ramesh.vandanapu@gmail.com

Joshua R. Omer

Senior Lecturer, School of Engineering and the Environment, Kingston University London, London, UK

j.r.omer@kingston.ac.uk

Mousa F. Attom

Professor, Department of Civil Engineering, American University of Sharjah, Sharjah, U.A.E mattom@aus.edu

Word count: 5962(inclusive of title, author affiliations, abstract, references, figure and table captions) 


\title{
Three dimensional finite element analyses of ground settlement and structural damage caused by irrigation of desert landscapes overlying collapsible soil strata
}

\begin{abstract}
Experience in the United Arab Emirates (UAE) has revealed the settlement risk to foundations built on collapsible strata when such strata become increasingly wet due to irrigation of lawns. This paper presents a numerical analysis of ground settlement at a location in the UAE where structural damage occurred, prompting a forensic investigation that involved borehole drilling and measurement of subsidence and structural failure characteristics. Midas ${ }^{T M} 3 D$ finite element (FE) program is used with field information from boreholes and irrigation specifications to simulate and predict the settlement profile for a typical pair of residential villas surveyed. Important factors are taken into account including the depths and thicknesses of the collapsible strata, the in-situ stresses, transient water flow, irrigation cycles, water table depth and the soil-structure mechanical properties. The maximum settlement of the boundary wall is predicted to be $157 \mathrm{~mm}$, which agrees closely with the measured value of $165 \mathrm{~mm}$. In addition, the predicted surface displacements are consistent with the observed ground and boundary wall deformation patterns.
\end{abstract}

Keywords: Collapsible soil; settlement; drip irrigation; finite element modeling; boundary walls. 


\section{Introduction}

Soils that possess collapse characteristics are found in many parts of the world such as USA, China, Central and South America, Russia, Africa, India and the Middle East (Mitchell and Soga 2005; Murthy 2010). On the one hand, collapsible soils in their natural condition may have adequate strength and hence usable in bearing load (Rezaei et al. 2012; Alain et al. 2012) but on the other hand, water can destroy the internal friction of such soils, resulting in a sudden reduction in volume and consequently settlement (Casagrande 1932; Barden et al. 1973; Mitchell 1976; Lawton et al. 1989; Pereira and Fredlund 2000; Jotisankasa 2005). Therefore, geotechnical engineers must understand the aforementioned unique behavior of collapsible soils in order to ensure a safe design and to put in place appropriate measures that may be necessary to manage the risks caused to a structure. Collapsibility due to water is generally shown by certain types of sands and silts whereas for clays the tendency is to expand rather than collapse when wetted. Water can enter a collapsible stratum through precipitation, irrigation activities, wastewater disposal, pipeline leakages, seepage from water bodies and groundwater table fluctuation (Adnan and Erdil 1992).

A number of researchers (Denisov 1951; Clevenger 1958; Gibbs 1961; Benites 1968; Handy 1973;

Houston et al. 1993; Das 2007) have attempted to use simple laboratory index tests, with varying degrees of success, to elucidate the settlement behaviour of collapsible soil. Some researchers (Reznik 1993; Houston et al. 1995; Mahmoud et al. 1995) have attempted to characterize collapsible soils based on field tests, which are generally more expensive than laboratory tests but better representative of in-situ conditions. Other researchers (Holtz and Hilf 1961; Jennings and Knight 1975; Jasmer and Ore 1987; Lawton et al. 1992; Anderson and Riemer 1995; Celestino et al. 2000; Reznik 2007; Gaaver 2012; Kalantari 2013; Rezaei et al. 2012; Vandanapu et al. 2017) have gone a step further to develop laboratory tests to simulate the effects of water on a collapsible 
layer and to formulate settlement prediction equations. With recent advances in computing and technology, other researchers (Alonso et al. 1990; Gens and Alonso 1992; Josa et al. 1992, Wheeler and Sivakumar 1995; Cui and Delage 1996; Wheeler 1996; Kato and Kawai 2000; Wheeler et al. 2003; Sun et al. 2007; Kakoli et al. 2009; Sheng 2011; Arairo et al. 2013; Rotisciani et al. 2015) have applied numerical modeling to analyze the influence of collapsible soil settlement on structural foundations and superstructures. Sophisticated numerical approaches, particularly finite element (FE) analysis offer numerous advantages not only because they can cope with complex soil-structure interaction mechanisms but also they take into account more factors than would be possible with simpler methods. These advantages are exploited in the present work, by focusing on 3D finite element treatment of structures and foundations built on a soil profile incorporating collapsible strata.

The problem of moisture-induced strength loss of a collapsible soil and consequent structural distress has been studied by several researchers, including (Houston et al. 2001; Noutash et al. 2010, Kalantari 2013, Vandanapu et al. 2016). In the current work, a case study is considered where various infrastructures (e.g. boundary walls and footpaths) at diverse locations in the UAE had suffered foundation failure or damage due to extreme settlement of collapsible strata occasioned by irrigation of adjacent landscapes. Therefore, an opportunity is taken here to implement a FE approach, with the aid of Midas ${ }^{T M}$ GTS NX (v1.1) 3D program (Midas 2014) to model the ground behaviour under simulated cycles of drip irrigation. For a realistic simulation, the irrigation input data (e.g. infiltration distribution and flow rates, sequence and timing of irrigation cycles) applied as exactly the same as those actually used by the landscape irrigation contractors at the sites where settlement problems occurred. Ultimately, the computed ground settlements are benchmarked against the actual values measured in the field. Additionally, the soil- 
structure module of Midas ${ }^{T M}$ is used to model the progressive collapse of masonry boundary that had been observed to have lost ground support from underneath. The aim of this was to understand the failure triggering mechanisms and hence suggest possible mitigation solutions.

\section{Case study of settlement of collapsible soils in UAE}

The project is a large scale infrastructure development located in Abu Dhabi (UAE), which comprises villas, shopping centres, indoor game complexes, open playgrounds, tennis courts, open green areas etc. Within a period of one year after completion of the construction and commissioning of the developments, many shallowly founded structures such as roads, hard landscapes (Fig. 1) and soft landscapes underwent subsidence, whilst boundary walls (Fig. 2 and 3) showed severe distress and cracking. By contrast, the villas, shopping centre and game complex were intact understandably because they were founded on piles embedded in rock. The maximum settlements in the hard landscapes, roads, and boundary walls were measured to be $75 \mathrm{~mm}, 100 \mathrm{~mm}$ and $165 \mathrm{~mm}$ respectively.

As a consequence of the aforementioned structural failures, the property owners engaged a geotechnical specialist company to investigate the causes of the problem and recommend methods of alleviating them. The company therefore drilled two exploratory boreholes to $15 \mathrm{~m}$ depth, establishing the groundwater table to be at an average depth of $1.5 \mathrm{~m}$ below the surface. The boreholes revealed the general stratification profile as shown in Table 1.

Initially there was some doubt by the geotechnical engineers as to whether the observed settlement problem could be blamed on infiltration of water from the irrigation of the adjacent landscapes. But at the same time it was noted that all the affected areas adjacent were in fact close to or within the irrigated landscape areas. Therefore, to eliminate any doubts, a trial part of the landscaped area was flooded with excess irrigation water (Fig. 4) and allowed time for the water to seep through, 
before performing a hydro-compaction process. This set of activities was carried out for 2 days, subsequent to which it was noticed that no more water seeped through the soil. In order to check the efficiency of this technique and to identify whether the underlying soils were responding to water ingress, a series of Mackintosh probe tests (Fig. 5) were carried out before and after the hydro-compaction. It was noticed that soils at depths above the water table had responded to water infiltration, except for few local pockets located at $0.4 \mathrm{~m}-0.6 \mathrm{~m}$ depths below ground level. This observation was clearly due to saturation effects on a uniquely responsive soil, rather than compaction effects (Vandanapu et al. 2016). Thus the presence of a collapsible layer, loosing interparticle strength when sufficiently wetted, above the water table was confirmed.

\section{Finite element modelling}

In an attempt to overcome some of the limitations of laboratory and field tests used in studying collapsible soils, the current work advances a radically different approach in the quest for a more realistic, powerful and reliable numerical solution for the above problem. The new strategy involves:

a. A comprehensive geotechnical model of twin villas with surrounding lawns with numerically simulated seepage intensity and cycle timing consistent with the actual specifications of the landscape irrigation.

b. 3D finite element soil-structure interaction analysis of the villas and their perimeter walls.

c. Non-linear finite element structural analysis of the perimeter walls, from where settlement predictions matching on-site measurements would serve to verify the validity of the analyses in (a) and (b) above.

\section{Geotechnical modelling}


Given the complexity of behaviour of collapsible soils and the incapability of laboratory tests to represent actual field conditions, it was considered that a fully coupled stress-seepage 3D finite element analysis would better deal with the problem and produce realistic simulations of the ground collapse response to irrigation. To tackle the complex problem, it was necessary to design an appropriate mathematical model and deploy a powerful 3D finite element program. For this purpose, Midas ${ }^{T M}$ GTS NX professional software (Midas 2014) was selected due to its advanced ability to cope with soil-structure problems involving 3-D transient seepage. The program can handle seepage and ground stress as a fully coupled analysis, giving outputs of pore pressure differentials and time dependent stress and deformation variations. Since the analysis does not follow the common assumption that steady pore water pressure is maintained, it is advantageous over other methods when transient seepage and stress analysis is significant in a problem. The fundamental relationships, compatibility equations and numerical schemes underlying Midas $^{T M}$ treatment of unsaturated materials and coupled stress-seepage under transient conditions are explained below.

\section{(1) Seepage parameters and relationships}

Though Darcy's law was originally derived for soils in saturated condition, many researches (Narasimhan 2004; Ghotbi et al. 2011) have shown that it can be applied to unsaturated soils also. In the present work, seepage flow is considered along the three mutually orthogonal directions $\mathrm{x}$, $y, z$ of the model and the permeability coefficient matrix is represented as shown in eq. (1) where only the diagonal components in each direction are considered.

$$
\mathrm{k}=\left[\begin{array}{ccc}
\mathrm{k}_{\mathrm{x}} & 0 & 0 \\
0 & \mathrm{k}_{\mathrm{y}} & 0 \\
0 & 0 & \mathrm{k}_{\mathrm{z}}
\end{array}\right]
$$


The permeability coefficients are a criterion for controlling the seepage rate and depend on moisture content and void ratio change, $\Delta \mathrm{e}$. Since moisture content is dependent on pore pressure, it follows that permeability values also change with pore pressure, $\Delta \mathrm{p}$. In the adopted model, $\Delta \mathrm{e}$ is used for consolidation analysis with fully coupled stress-seepage analysis. Values of $\Delta \mathrm{e}$ are calculated from the initial condition defined in the input. The unsaturated permeability coefficient is calculated from eq. (2).

$$
\mathrm{k}=10^{\frac{\Delta \mathrm{e}}{\mathrm{c}_{\mathrm{k}}}} \mathrm{k}_{\mathrm{r}}(\mathrm{p}) \mathrm{k}_{\mathrm{sat}}
$$

where,

$$
\begin{aligned}
& k=\text { unsaturated permeability coefficient } \\
& \Delta e=\text { change in void ratio } \\
& c_{k}=\text { the term that defines the permeability ratio as a function of } \Delta e \\
& k_{r}(p)=\text { permeability ratio function depending on } \Delta p \\
& k_{s a t}=\text { saturated permeability coefficient }
\end{aligned}
$$

In the analysis, volumetric water content is defined in terms of the ratio between the water volume and total volume as shown in eq. (3).

$$
\theta=\frac{V_{w}}{V}=n S
$$

where,

$$
\begin{aligned}
& \begin{array}{l}
\theta \\
=
\end{array} \text { Volumetric water content } \\
& V_{w}=\text { Water volume } \\
& V=\text { Total volume } \\
& n=\text { Porosity } \\
& S=\text { Degree of saturation }
\end{aligned}
$$


Calculation of element seepage and consolidation utilize the volumetric water content for pore pressure (p), and requires differentiation of eq. (3) and expressing the result using porosity and degree of saturation as shown in eq. (4).

$$
\frac{\partial \theta}{\partial \mathrm{p}}=s \frac{\partial \mathrm{n}}{\partial \mathrm{p}}+n \frac{\partial \mathrm{S}}{\partial \mathrm{p}}
$$

The first term of the right hand side of eq. (4) represents the rate of change of the volumetric water content for the saturated condition. It is defined by a parameter called the specific storage $\left(\mathrm{S}_{\mathrm{s}}\right)$, which represents the volumetric ratio of the water movement in the ground due to the pore pressure head change [eq. (5)].

$$
S \frac{\partial \mathrm{n}}{\partial \mathrm{p}}=\frac{\partial V_{v}}{\partial \mathrm{h}} \frac{\partial \mathrm{h}}{\partial \mathrm{p}}=n \frac{S_{S}}{\gamma}
$$

where,

$$
\begin{aligned}
& V_{v}=\text { Void volume } \\
& h=\text { Pore pressure head }
\end{aligned}
$$

The second term of the right hand side of eq. (4) represents the slope of the volumetric water content for the unsaturated condition. This value uses the slope of the soil-water characteristic curve represents the relationship between the volumetric water content and pore pressure for unsaturated conditions. In the model, adopted in Midas $^{T M}$ the non-linear characteristics of unsaturated soils are represented by various forms of ductile functions including: pressure head versus water content, water content versus permeability ratio function or pressure head versus saturation and saturation versus permeability ratio function.

(2) Modelling of seepage elements

Various relationships are used in Midas ${ }^{T M}$ to model elements for analysis of pore water seepage in both saturated and unsaturated soils. An important parameter involved here is the mass concentration of water in the ground, $\rho_{\mathrm{wnS}}$. This can be defined considering the continuity 
equation of mass for micro-volumes. Continuity requires that the amount of water escaping from the micro-volume equals the change in mass concentration [eq. (6)].

$$
\nabla^{T}\left(\rho_{\mathrm{w}} \mathrm{q}\right)=\frac{\partial}{\partial \mathrm{t}}\left(\rho_{\mathrm{w}} \mathrm{nS}\right)
$$

where, $q=$ Seepage flow velocity component

The right term of the eq. (6) can be expressed using the changes in water density, degree of saturation and porosity with time as shown in eq. (7).

$$
\frac{\partial}{\partial \mathrm{t}}\left(\rho_{\mathrm{w}} \mathrm{nS}\right)=n S \frac{\partial \rho_{\mathrm{w}}}{\partial \mathrm{t}}+\rho_{\mathrm{w}} \mathrm{n} \frac{\partial \mathrm{s}}{\partial \mathrm{t}}+\rho_{\mathrm{w}} S \frac{\partial \mathrm{n}}{\partial \mathrm{t}}
$$

The adopted model is based on Darcy's law, considering porosity change with time only in the formulation process for element consolidation analysis. Pore pressure (p) is a variable in the seepage analysis, and the governing equation for the analysis is derived from Darcy's law as shown in eq. (8).

$$
\frac{1}{\gamma_{w}} \nabla^{\mathrm{T}}(\mathrm{k} \nabla \mathrm{p})-\nabla^{\mathrm{T}}\left(\mathrm{k} n_{g}\right)=\left(\frac{n S}{\rho_{w}} \frac{\partial \rho_{w}}{\partial \mathrm{p}}+n \frac{\partial S}{\partial p}\right) \frac{\partial p}{\partial t}
$$

where,

$$
\begin{aligned}
& k=\text { coefficient of permeability matrix } \\
& n_{g}=\text { unit vector in gravitational direction }
\end{aligned}
$$

To define the initial conditions for transient seepage analysis the ground water level is defined. Then steady-state analysis results are used at the initial time step load.

\section{(3) Modelling of consolidation elements}

The analyses with Midas ${ }^{T M}$ specifically use consolidation continuum elements to simulate stressseepage coupled phenomena. During this process, consolidation analysis is fundamentally performed as a nonlinear analysis. Pore pressures related to both the steady state and transient states are identified and so classified. The initial water level defined in the model is considered as 
the steady state pore pressure, and the excess pore pressure during consolidation is considered as the transient state pore pressure. The transient state is the fundamental state of consolidation analysis. On completion of the element consolidation analysis stage, the results are expressed with reference to a user specified coordinate system.

With reference to the problem on hand, the sizes of all components of the geotechnical model were defined to match the respective on-site dimensions. The components included the twin-villa complex with boundary walls, hard landscapes, soft landscapes (drip irrigated areas) and respective car parks (Fig. 6).

The various control settings and parameter values used in modelling are described in the following sections:

\section{Soil properties}

Relevant parameters for various soils (Table 2) were derived from the ground investigation report produced by the specialist geotechnical investigation company in the UAE. Where laboratory soil test data were unavailable, values were assessed using appropriate correlation charts and tables.

\section{Loads of various infrastructures}

Loads of villas, hard landscapes, boundary walls and car parks were inputted to model as $5 \mathrm{kN} / \mathrm{m}^{2}$ (very less in magnitude), $10 \mathrm{kN} / \mathrm{m}^{2}, 80 \mathrm{kN} / \mathrm{m}^{2}$ and $60 \mathrm{kN} / \mathrm{m}^{2}$ respectively. All values were derived reasonably based on the dimensions of the structures and respective unit weights of their elements. It was noted that the magnitude of villa loads acting on the surface of the model was likely to be small since much of this load would have been resisted by the supporting piles and hence transferred to the bedrock. 


\section{Meshing details}

All soil layers were fine-meshed using tetrahedral elements with nodes connecting automatically across elements in the adjacent solids. This ensured appropriate nodal connectivity in the whole model (Fig. 7). Refinement of mesh was carried out using several trials and no further refinement was done once no significant change was noticed in results with further decrease in mesh size.

\section{Drip Irrigation Simulation}

Based on information obtained from the landscape irrigation companies involved, various infiltration parameters for defined areas were assessed and for input into the program, where specifically:

a. the input flow rate was determined to be $13 \mathrm{l} / \mathrm{m}^{2} /$ day (i.e. litres per square metre per day)

b. the $13 \mathrm{l} / \mathrm{m}^{2} /$ day flow rate was applied in two identical 30 minute cycles per a day, i.e. cycle 1 at $6.5 \mathrm{l} / \mathrm{m}^{2}$ in the morning and cycle 2 at $6.5 \mathrm{l} / \mathrm{m}^{2}$ in the evening. There was no irrigation in between the two cycles in any day.

In the program, the consequent transient flow from the irrigation process was modelled using the ‘seepage boundary’ function (Fig. 8), which required assigning a value of flow rate per unit area of a defined flux surface (soft landscaped areas in the current model) of perpendicular water entry into the uppermost stratum considered.

\section{Boundary conditions of model}

In order to simulate the real situation in the field, appropriate boundary conditions of the mesh sets were defined by constraining displacements in: (i) the $x$ direction for both the left and right faces of the geometry model, (ii) the $y$ direction for both the front and back faces of the model, (iii) both the $x$ and $y$ directions for the bottom boundary of the model. Thus displacements were permitted in the $\mathrm{z}$ direction only, so that the calculated soil surface deformation would be interpreted as either settlement or heave. 
Now, although in reality the infiltration through the soil would potentially be three directional, since the ground surface at the actual site is reasonably flat, the flow would be predominantly along the gravity direction. Hence, to simulate this, the bottom face of the model was selected as a review boundary (Fig. 9), in order to enable customisation of seepage direction with respect to boundary surface considered (e.g. flow in a defined direction perpendicular to a specified plane).

Since the native soils at the UAE site analysed were principally free draining and dry silty sands, it was reasonable to set the total head as zero for all the 29 boundaries ( 4 sides of the model times 7 stratum faces per side plus the bottom face) as seen in Fig. 10. This guaranteed zero excess pore water pressure associated with loading.

Analysis methodology

For the model to closely represent reality, the analysis was carried out in a staged construction sequence as follows: (i) stage one equivalent to the in-situ conditions and accounts for the weights of the soil layers, (ii) stage two represents installation of the villas and all other structures including boundary walls, hard landscapes etc. and (iii) stage three simulating the cycles of transient irrigation water flow.

In order to determine the soil deformations associated exclusively with the transient drip irrigation, ground settlements caused by soil self-weights and structures were nullified from the model using the 'clear displacement' option (Fig. 11). Finally, ground settlements were monitored at the end of every irrigation cycle or until there was either (a) no further settlement change or (b) the solution started to diverge, for the set convergence criteria, for the subsequent irrigation cycle.

\section{Results and discussion}

From the software calculation results, the ground settlement beneath the boundary walls at three different water depths, viz. 1.5m, 2.0m and 3.0m were summarised. Figure 12 maps out a specimen result of magnitudes of ground settlement beneath a boundary wall at the end of the $17^{\text {th }}$ irrigation 
cycle, which corresponds to a water table depth of $1.5 \mathrm{~m}$. Figure 13 shows the calculated trends of variation of settlement beneath boundary wall versus number of irrigation cycles, for three particular water table levels. It is evident that the number of irrigation cycles required for the supporting ground to exhibit total collapse increases with increasing water table depth. The observed suddenness of bearing capacity loss, coupled with strong sensitivity to water table position, is an indication of the presence of collapsible layer(s) in the soil profile. Vandanapu et al. (2017) observed a similar trend from laboratory tests on a collapsible soil sandwiched between two other layers and loaded under different water table levels and infiltration rates. Figure 13 also reveals that, after sufficient wetting in 4-5 irrigation cycles, the ground surface settlement at the end of a given irrigation cycle increased with increasing water table depth. This evidences that once the collapsible stratum had been saturated sufficiently to fail with the ground water table at a certain depth, there was very little additional settlement with increasing water table depth due to the relatively less sensitivity of the non-collapsible layers to water table rise. It is interesting to note that the calculated maximum settlement beneath the boundary wall was $157 \mathrm{~mm}$, which compares favourably with the measured value of $165 \mathrm{~mm}$ on site. This gave confidence that the 3D finite element model and the assessed parameters are reliable and consistent with the real ground behaviour.

\section{Structural modelling of boundary walls}

The forensic geotechnical investigations at the site in UAE showed that the boundary walls around the villas suffered the greatest deformation as a result of irrigation-induced settlement of the collapsible strata. As seen in Fig. 3, as the soil beneath the boundary walls settled, the top surface of the wall remained unaffected and horizontal. Furthermore there was no evidence of the entire wall sagging as a unit. Instead, extreme movements occurred along the masonry bedding joints at 
$300-400 \mathrm{~mm}$ above the ground. It would have been expected that the wall would deform in a different pattern since both of its ends were supported on the settling soil. Hence, to examine how the observed failure mechanism was possible, further analysis was undertaken using a separate non-linear structure analysis module of Midas ${ }^{T M}$ finite element program.

\section{Technical details of modelling}

A 2D finite element analysis of boundary wall of actual size (6.0 m length and $2.4 \mathrm{~m}$ height) on site was carried out in the software using quadrilateral mesh elements of $50 \mathrm{~mm}$ in size. The size of the mesh was decided based on different trials. Initially a coarser mesh was analysed and made finer after each trial. Once no further significant change in results was noticed even after refining the mesh, mesh size was finalized and no further trials carried out. All vertical joints in the brick masonry were modelled as staggered in position such that no two vertical joints in consecutive courses will join. All mortar joints were modelled as interface elements and discrete cracking approach was used. Constraints on both end of the wall were taken as 'pinned' with three degrees of freedom in translation along all axes. Nonlinear static analysis was performed with material and geometric nonlinearities. The entire self-weight of the wall was imposed as load in 20 equal steps and maximum number of iterations per load step was limited to 30. Newton Raphson iteration scheme was used and convergence criterion of the analysis was based on 'energy norm'.

\section{Modelling parameters}

Various parameters used in the analysis are shown in Table 3. 


\section{Understanding and analysis methodology}

It was known that the boundary walls were directly supported on strip foundations bearing on the ground that started settling when the collapsible stratum lost its structural strength under the influence of seepage from surface irrigation. However, the observed deformation pattern indicated of the boundary wall, where the ends remained intact as the lowermost masonry courses sheared off, indicated that the wall ends were well tied and that self-supporting or interlocking mechanisms prevailed across most of the masonry courses. Also, in reality the entire soil underneath the boundary wall would neither commence settlement at the same time nor have a uniform settlement rate. Hence, in the first part of the analysis a hypothetical situation was assumed where the complete wall lost support due to settlement of the supporting soil below.

Therefore, to improve the calculation results, a further analysis was carried out properly considering soil-structure interaction influences. The interaction meant that, as the soil support was gradually lost below the wall base, stresses within the wall were redistributed such that more load was transferred to the end ties, with the wall increasingly mobilising its own self-supporting capability until the mortar joints failed. These mechanisms were modelled using a non-linear structure analysis module of Midas ${ }^{T M}$ by specifying input values of incremental wall self-weights and performing calculations to monitor the consequent load transfer and deformation response of the wall. In the analysis, the wall end constraint conditions were defined as "pinned" before imposing self-weights in 20 equal steps, each equivalent to $5 \%$ of the actual weight of the wall.

\section{Results and discussion}

Figure 14 shows the calculated maximum wall settlements corresponding to various increments of percentage self-weight. It can be seen that the graph is bi-linear, with the wall settlement initially increasing at a marginal rate but once the percentage self-weight reached 35\%, there the wall 
settlement increased suddenly from $0.7 \mathrm{~mm}$ to $15.65 \mathrm{~mm}$. This is equivalent to a 22 times increase in settlement for a 5\% increase in applied weight from 35\% to 40\%. Figure 15 shows the output deformation pattern of the wall at $40 \%$ weight increment corresponding to the drastic settlement increase. Essentially the wall had failed at this stage because of continuous divergence of subsequent calculation solutions and unrealistic settlement outputs producing incompatible failure patterns.

It can be seen that the predicted failure patterns of the wall (Fig. 15) are similar to the site observations (Fig. 3), where failure of mortar bedding joints caused complete dislocation of the lower masonry courses while other parts of the wall remained largely intact. The close agreement between the measured and predicted mechanisms gave confidence that the suggested finite element analysis approach and parameter values used in $\operatorname{Midas}^{T M}$ are consistent with reality. Unsurprisingly, the structural distress was not due to rigid settlement of the wall as a unit but rather failure of the mortar joints in response to extreme settlements and redistribution of stresses in the wall and its ties. 


\section{Conclusions}

Numerical analysis of ground settlement and structural distress has been successfully carried out using data from a case study in Abu Dhabi (UAE). At the site considered, various shallowly founded structures including boundary walls, roads and hard landscapes had suffered considerable deformation due to infiltration from irrigation water which saturated underlying collapsible strata sufficiently to lose inter-particle strength hence subside significantly. The analysis involved 3D finite element representation of the ground profile, supported structures and transient inflow of irrigation water to raise the water table above the collapsible strata. Complexity of the mechanisms of collapsible soils coupled with limited literature on settlement necessitated the use of the latest powerful and research oriented software which Midas ${ }^{T M}$ GTS NX offered. With careful interpretation of the site investigation and landscape irrigation specifications from the case study, the program was used to analyse the ground settlements under sustained cycles of irrigation. The computed settlements were found to be in close agreement with the measured ones at specific positions on the site. Computation results showed that the sudden loss of strength of the collapsible layer required the water table to reach a certain depth, which corresponded to a certain number of irrigation cycles. Further increase of water table depth would have increasingly less impact on settlement since the collapsible layer would have already lost its full inter-particle strength.

Additionally, boundary walls were separately modelled using the non-linear structural analysis module of Midas $^{T M}$ software. This was in order to examine why the walls failed in the patterns observed at the sites of the case study. It was shown that not only was the predicted failure mode consistent with the actual site observation but also the magnitudes of the calculated and measured maximum settlements were very close. Since the failure of the walls was due to loss of mortar joint strength, the distress witnessed might have been avoided or lessened had the walls been 
constructed with either (a) lightweight masonry unit materials, or (b) a supporting ground beam resting on deep foundations, comparable to the foundation system of the villas that were unaffected by the superficial soil collapse.

With the discernibly accurate results obtained, the proposed 3D finite element approach has demonstrated capability to simulate the behaviour of the real ground and this success provides an alternative and superior solution to empiricism based on laboratory or field tests. The current study forms part of an on-going doctoral research work aimed contributing new understanding of the settlement behaviour of collapsible desert soils underlying irrigated landscapes. It is hoped that further solutions will be developed to assist engineers safeguard infrastructure and prevent the kind of distresses witnessed in the UAE case study area. 


\section{References}

Adnan, A.B., and Erdil, R.T. 1992. "Evaluation and control of collapsible soils." Journal of Geotechnical Engineering 118 (10): 1491-1504. doi: 10.1061/(ASCE)07339410(1992)118:10(1491)

Alain, E.H., Pao-Tsung, H., Rachael, B., and Maria, C.S. 2012. Identification and behavior of collapsible soils. Joint Transportation Research Program. Indiana Department of Transportation and Purdue University, Report Number: FHWA/IN/JTRP-2011/12. https://doi.org/10.5703/1288284314625

Alonso, E.E., Gens, A., and Josa, A.A. 1990. "Constitutive model for partially saturated soils.” Géotechnique 40 (3): 405-430. doi: 10.1680/geot.1990.40.3.405

Anderson, S.A., and Riemer, M.F. 1995. "Collapse of saturated soil due to reduction in confinement.” Journal of Geotechnical Engineering 121 (2): 216-219. doi:10.1061/(ASCE)0733-9410(1995)121:2(216)

Arairo, W., Prunier, F., Djéran-Maigre, I., and Darve, F. 2013. “A new insight into modelling the behaviour of unsaturated soils.” International Journal for Numerical and Analytical Methods in Geomechanics 37 (16): 2629-2654. doi: 10.1002/nag.2151

Barden, L., McGown, A., and Collins, K. 1973. “The collapse mechanism in partly saturated soil.” Engineering Geology 7 (1): 49-60. doi: 10.1016/0013-7952(73)90006-9

Benites, L.A. 1968. "Geotechnical properties of the soils affected by piping near the Benson area, Cochise County, Arizona.” M.S. Thesis, University of Arizona, Tucson, United States of America. http://hdl.handle.net/10150/551987

Casagrande, A. 1932. "The structure of clay and its importance in foundation engineering." Journal of Boston Society of Civil Engineers, 19 (4): 168-209. 
Celestino, R., Claudio, M., and Filippo, V. 2000. "Experimental behaviour and modelling of an unsaturated compacted soil.” Canadian Geotechnical Journal 37 (4): 748-763. doi:10.1139/t00-004

Clevenger, W.A. 1958. "Experiences with loess as foundation material." Transactions of the American Society of Civil Engineers 123 (1): 151-169.

Cui, Y. J., and Delage, P. 1996. "Yielding and plastic behavior of an unsaturated compacted silt." Géotechnique 46 (2): 291-311. doi: 10.1680/geot.1996.46.2.291

Das, B.M. 2007. Principles of foundation engineering. Boston: PWS publishing company.

Denisov, N.Y. 1951. The engineering properties of loess and loess loams. Moscow: Gosstroiizdat.

Gaaver, K.E. 2012. “Geotechnical properties of Egyptian collapsible soils.” Alexandria Engineering Journal 51 (3): 205-210. doi: 10.1016/j.aej.2012.05.002

Gens, A., and Alonso, E.E. 1992. “A framework for the behavior of unsaturated expansive clays.” Canadian Geotechnical Journal 29 (6): 1013-1032. doi: 10.1139/t92-120

Ghotbi, A.R., Omidvar, M., and Barari, A. 2011. "Infiltration in unsaturated soils - An analytical approach.” Computers and Geotechnics 38 (6): 777-782. doi: 10.1016/j.compgeo.2011.05.007

Gibbs, H.J. 1961. Properties which divide loess and dense uncemented soils. Earth laboratory report EM-658, Bureau of Reclamation, U.S. Department of the Interior.

Handy, R. L. 1973. “Collapsible loess in Iowa.” Soil Science Society of America Journal 37 (2): 281-284. doi:10.2136/sssaj1973.03615995003700020033x

Holtz, W.G., and Hilf, J.W. 1961. "Settlement of soil foundations due to saturation. Proceedings of $5^{\text {th }}$ International Conference on Soil Mechanics and Foundation Engineering, Paris, 673679. 
Houston, S.L., Hisham, H.H.M., and Houston, W.N. 1995. “Down-hole collapse test system.” Journal of Geotechnical Engineering 121 (4): 341-349. doi: 10.1061/(ASCE)0733$\underline{9410(1995) 121: 4(341)}$

Houston, S.L., Houston, W.N., Zapata, C.E., and Lawrence, C. 2001. “Geotechnical engineering practice for collapsible soils.” Geotechnical and Geological Engineering, 19 (3-4): 333-355. doi: 10.1023/A:1013178226615

Houston, W.N., Mahmoud, H.H., and Houston, S.L. 1993. “Laboratory procedure for partialwetting collapse determination.” Unsaturated soils, Special Geotechnical Publication, ASCE 39 : 54-63. doi: 10.1061/(ASCE)0733-9410(1989)115:9(1252)

Jasmer, R., and Ore, H.B. 1987. "Hydro-compaction hazards due to collapsible loess in SouthEastern Idaho.” Proceedings of the $23^{\text {rd }}$ Symposium on engineering geology and soils engineering, Logan, Utah, 461-475.

Jennings, J.E., and Knight, K. 1975. “A guide to construction on or with materials exhibiting additional settlements due to collapse of grain structure.” Proceedings of $6^{\text {th }}$ Regional Conference for Africa on Soil Mechanics and Foundation Engineering, Johannesburg, 99-105.

Josa, A., Balmaceda, A., Gens, A., and Alonso, E.E. 1992. “An elastoplastic model for partially saturated soils exhibiting a maximum of collapse.” Proceedings of the $3^{\text {rd }}$ International Conference on Computational Plasticity. Barcelona, 815-826.

Jotisankasa, A. 2005. “Collapse behavior of a compacted silty clay.” PhD Thesis, Imperial College, London.

Kakoli, S.T.N., Hanna, A.M., and Adayat, T. 2009. "Simulation of collapsible soils subjected to inundation." Proceedings of the $17^{\text {th }}$ International Conference on Soil Mechanics and 
Geotechnical Engineering, Alexandria, Egypt, 3431 - 3434. doi: 10.3233/978-1-60750-031$\underline{5-3431}$

Kalantari, B. 2013. "Foundations on collapsible soils: a review." Proceedings of the Institution of Civil Engineers-Forensic Engineering 166 (2): 57-63. doi:10.1680/feng.12.00016

Kato, S., and Kawai, K. 2000. "Deformation characteristics of a compacted clay in collapse under isotropic and triaxial stress state." Soils and Foundations 40 (5): 75-90. doi: $\underline{10.3208 / \text { sandf.40.5_75 }}$

Lawton, E.C., Fragaszy, R.J., and Hardcastle, J.H. 1989. “Collapse of compacted clayey sand.” Journal of Geotechnical Engineering, ASCE, 115 (9): 1252-1267. doi:10.1061/(ASCE)0733$\underline{9410(1989) 115: 9(1252)}$

Lawton, E.C., Fragaszy, R.J., and Hetherington, M.D. 1992. "Review of wetting-induced collapse in compacted soil.” Journal of Geotechnical Engineering 118 (9): 1376-1394. doi: 10.1061/(ASCE)0733-9410(1992)118:9(1376)

Mahmoud, H., Houston, W.N., and Houston, S.L. 1995. “Apparatus and procedure for an in-situ collapse test.” Geotechnical Testing Journal, ASTM, 121 (4): 431-440. doi: $\underline{10.1520 / G T J 11018 J}$

Midas Information Technology Co., Ltd. 2014. GTS NX-GeoTechnical analysis System New eXperience, Version 1.1. User’s Manual. Bundang-gu, Seongnam-si, Gyeonggi-do, Korea.

Mitchell, J.K., and Soga, K. 2005. Fundamentals of soil behavior. New York: Wiley.

Mitchell, J.K. 1976. Fundamentals of soils behavior. New York: Wiley.

Murthy, V.N.S. 2010. Soil mechanics and foundation engineering. New Delhi: CBS publishers and distributors. 
Narasimhan, T.N. 2004. “Darcy's Law and Unsaturated Flow.” Vadose Zone Journal, 3 (4): 1059. doi: $\underline{10.2113 / 3.4 .1059}$

Noutash, M.K., Hajialilue, B.M., and Cheshmdoost, M. 2010. "Prepounding of canals as a remediation method for collapsible soils.” Proceedings of the $4^{\text {th }}$ International Conference on Geotechnical Engineering and Soil mechanics, Tehran, Iran.

Pereira, J.H.F., and Fredlund, D.G. 2000. "Volume change behavior of collapsible compacted gneiss soil.” Journal of Geotechnical and Geoenvironmental Engineering, ASCE, 126 (10): 907-916. doi:10.1061/(ASCE)1090-0241(2000)126:10(907)

Rezaei, M., Ajalloeian, R., and Ghafoori, M. 2012. “Geotechnical properties of problematic soils: emphasis on collapsible cases.” International Journal of Geosciences, 3 (1): 105-110. doi:10.4236/ijg.2012.31012.

Reznik, Y.M. 2007. “Influence on physical properties on deformation characteristics of collapsible soils.” Engineering Geology, 92 (1-2): 27-37. doi:10.1016/j.enggeo.2007.03.001

Reznik, Y.M. 1993. "Plate-load tests of collapsible soils.” Journal of Geotechnical Engineering 119 (3): 608-615. doi: 10.1061/(ASCE)0733-9410(1993)119:3(608)

Rotisciani, G.M., Sciarra, G., Casini, F., and Desideri, A. 2015. “Hydro-mechanical response of collapsible soils under different infiltration events.” International Journal for Numerical and Analytical Methods in Geomechanics 39 (11): 1212-1234. doi:10.1002/nag.2359

Sheng, D. 2011. "Review of fundamental principles in modeling unsaturated soil behaviour.” Computers and Geotechnics 38 (6): 757-776. doi:10.1016/j.compgeo.2011.05.002

Sun, D.A., Sheng, D.C., Cui, H.B., and Sloan, S.W. 2007. “A density-dependent elastoplastic hydro-mechanical model for unsaturated compacted soils.” International Journal for 
Numerical and Analytical Methods in Geomechanics 31 (11):1257-1279. doi: 10.1002/nag.579

Vandanapu, R., Omer, J.R., and Attom, M.F. 2016. “Geotechnical case studies: emphasis on collapsible soil cases.” Proceeding of Institution of Civil Engineers-Forensic Engineering 169 (3): 103-110. doi:10.1680/jfoen.16.00011

Vandanapu, R., Omer, J.R., and Attom, M.F. 2017. "Laboratory simulation of irrigation-induced settlement of collapsible desert soils under constant surcharge.” Geotechnical and Geological Engineering 35 (6): 2827-2840. doi: 10.1007/s10706-017-0282-0

Wheeler, S.J. 1996. "Inclusion of specific water volume within an elasto-plastic model for unsaturated soil.” Canadian Geotechnical Journal 33 (1): 42-57. doi:10.1139/t96-023

Wheeler, S.J., Sharma, R.J., and Buisson, M.S.R. 2003. "Coupling of hydraulic hysteresis and stress-strain behaviour in unsaturated soils.” Géotechnique 53 (1): 41-54. doi: 10.1680/geot.2003.53.1.41

Wheeler, S.J., and Sivakumar, V. 1995. “An elasto-plastic critical state framework for unsaturated soil.” Géotechnique, 45 (1): 35-53. doi:10.1680/geot.1995.45.1.35 


\section{Figure Captions}

Fig. 1 Subsidence of hard landscape adjacent to a villa

Fig. 2 Initiation of cracking in a boundary wall

Fig. 3 Severely distressed boundary walls due to cracking and settlement

Fig. 4 Investigative flooding of landscaped areas

Fig. 5 Mackintosh probe test results (Vandanapu et al. 2016)

Fig. 6 Geometric model of the twin-villa complex and underlying strata

Fig. 7 Meshed model incorporating soil profile and supported structures

Fig. 8 Seepage boundary conditions of the model (mesh un-selected for clear view)

Fig. 9 Direction simulation of seepage in the model (mesh un-selected for clear view)

Fig. 10 Seepage boundary conditions of the model (mesh un-selected for clear view)

Fig. 11 Staged construction sequences in the analysis

Fig. 12 Settlement of soil under boundary wall at the end of $17^{\text {th }}$ irrigation cycle with ground water at $1.5 \mathrm{~m}$ depth

Fig. 13 Settlement versus irrigation cycles at various depths of groundwater table.

Fig. 14 Wall settlements at various percentage of self-weights

Fig. 15 Failure pattern of wall at $40 \%$ self-weight

\section{Table captions}

Table 1 General stratification profile of the case study site

Table 2 Input soil parameters in the analysis

Table 3.Input parameters for the soil-structure interaction analysis of the boundary wall 


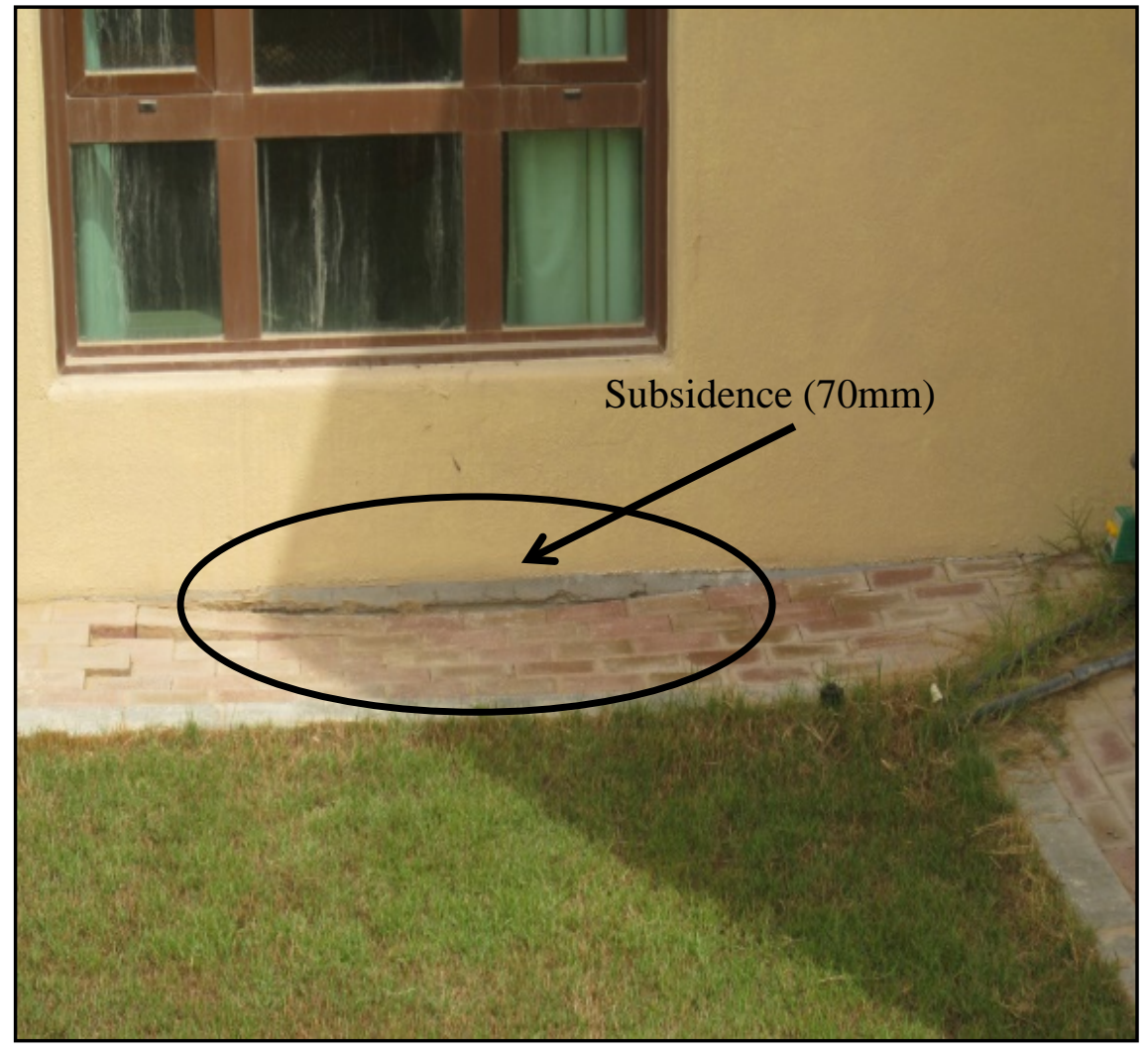

1 Subsidence of hard landscape adjacent to a villa 


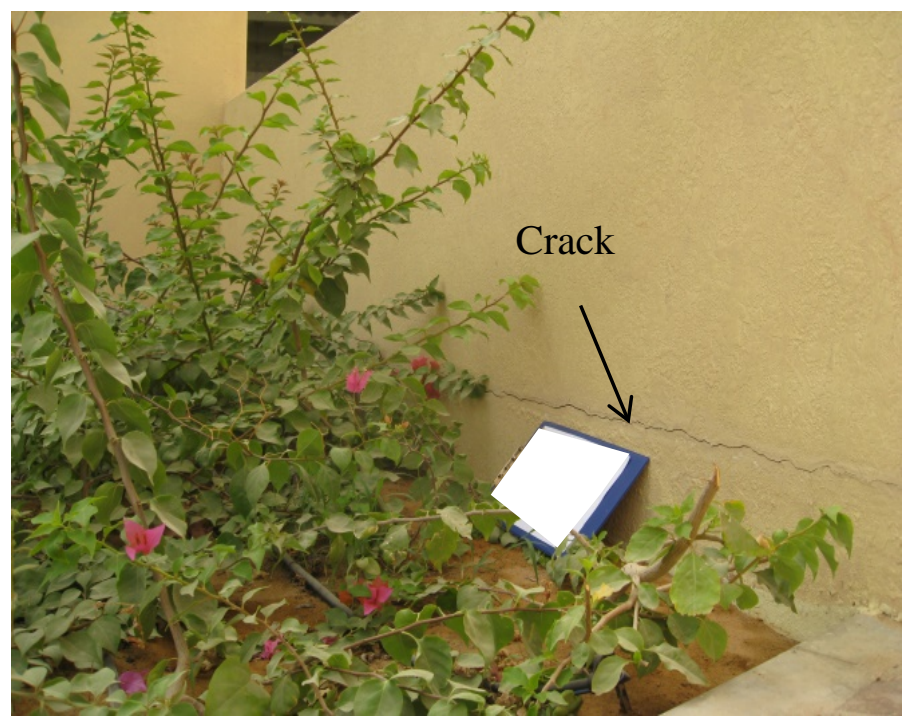

2 Initiation of cracking in a boundary wall 

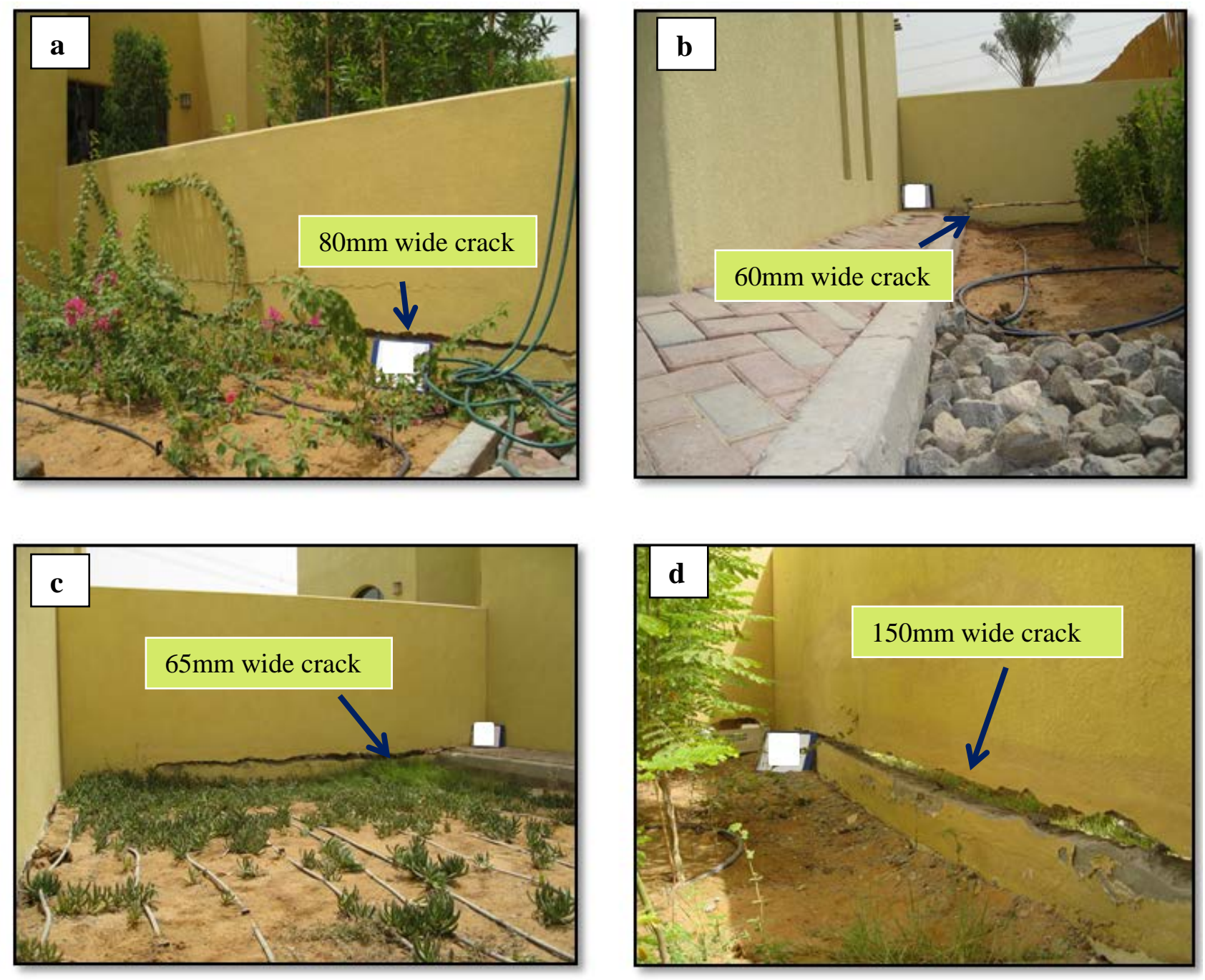

3 Severely distressed boundary walls due to cracking and settlement 


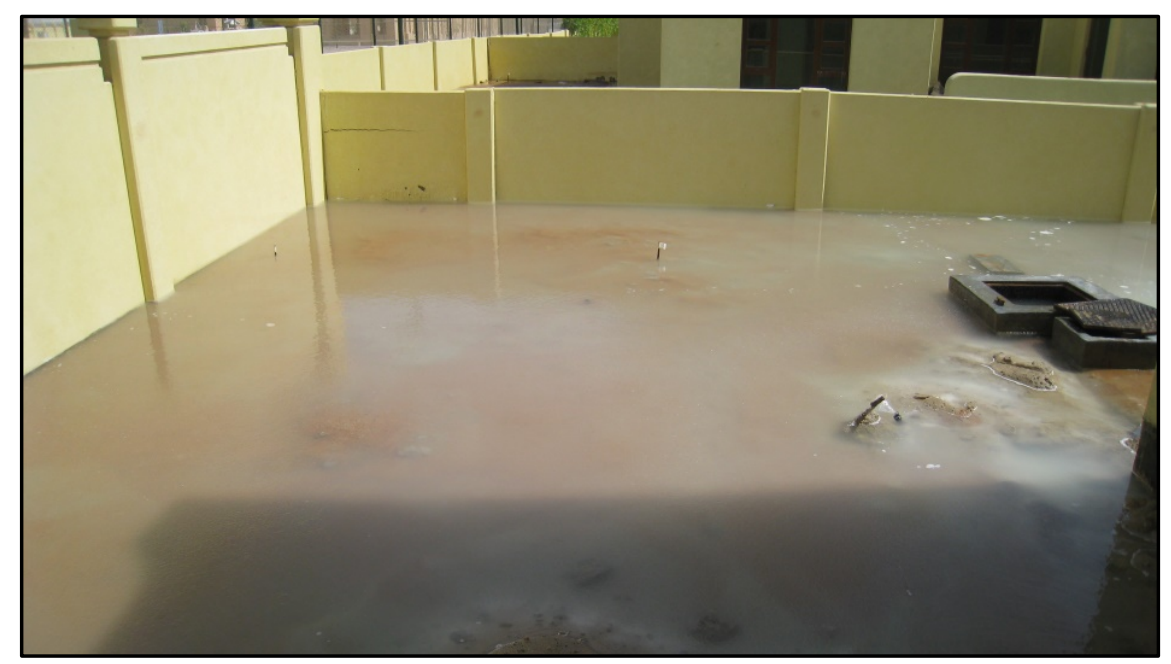

4 Investigative flooding of landscaped areas 


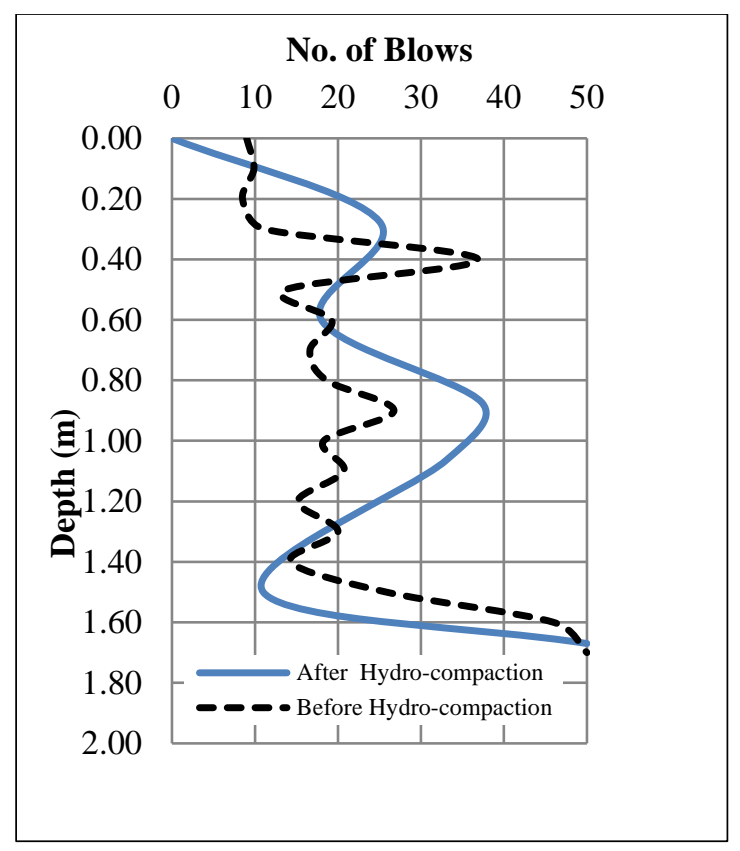

5 Mackintosh probe test results (Vandanapu et al. 2016) 


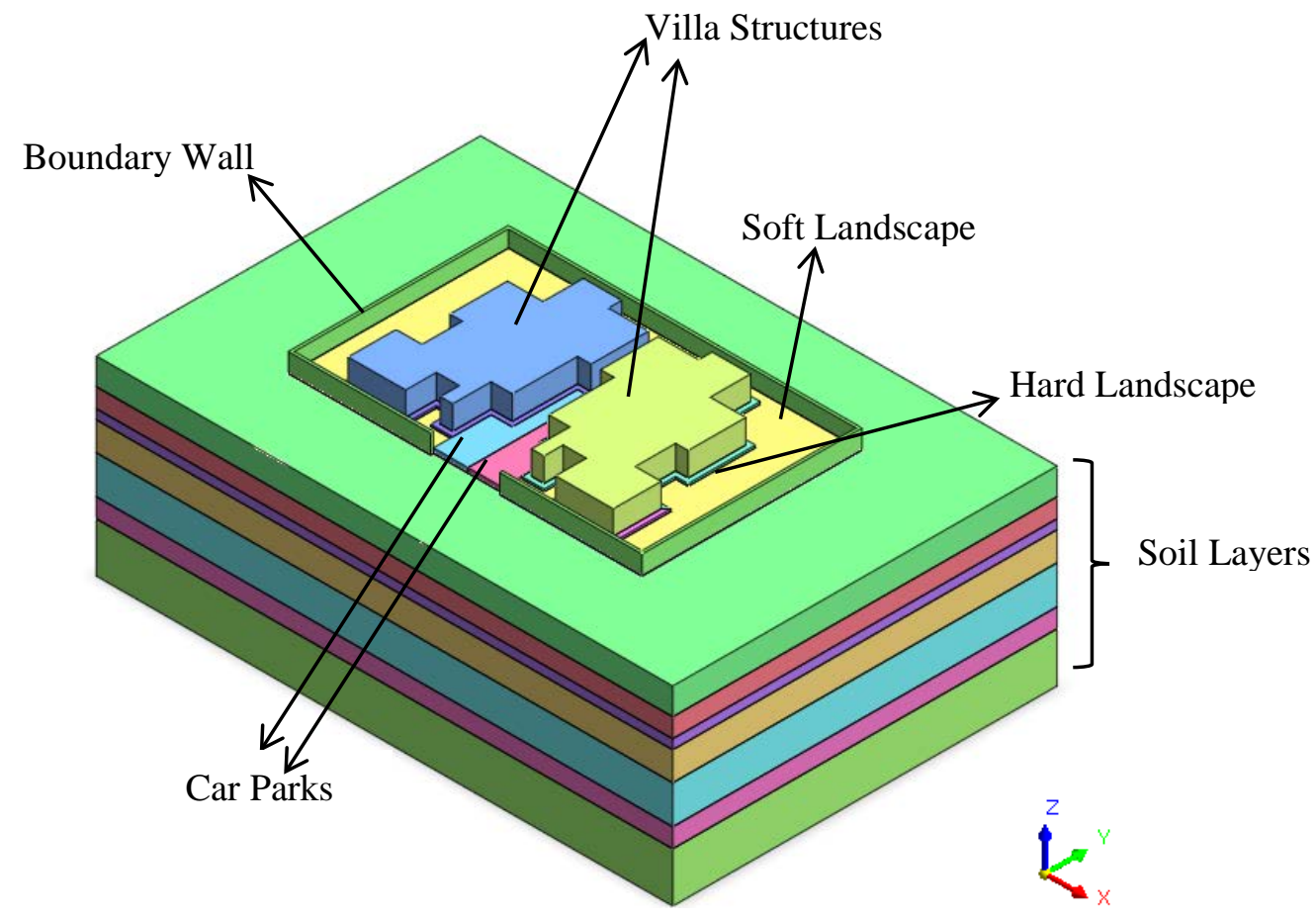

6 Geometric model of the twin-villa complex and underlying strata 


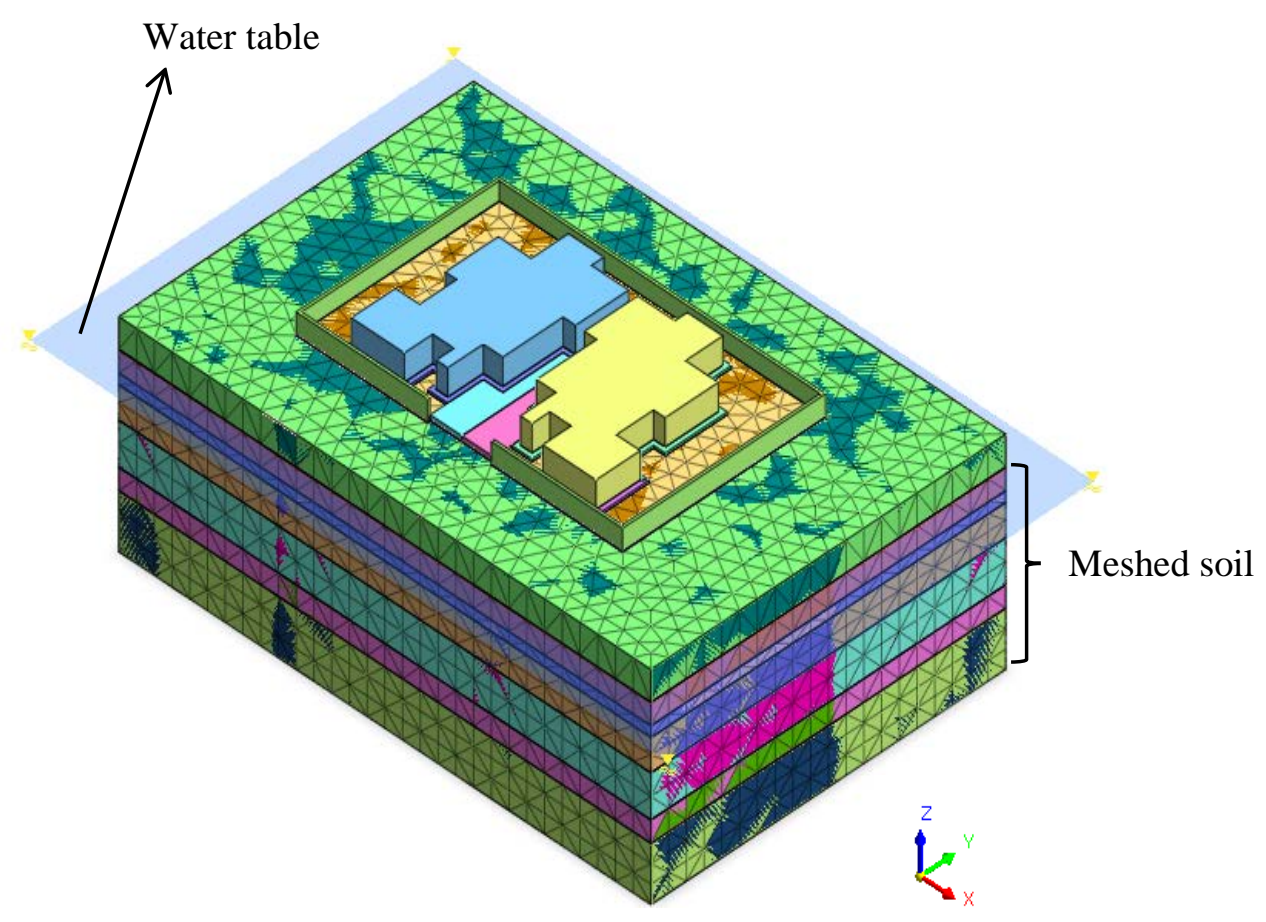

7 Meshed model incorporating soil profile and supported structures 


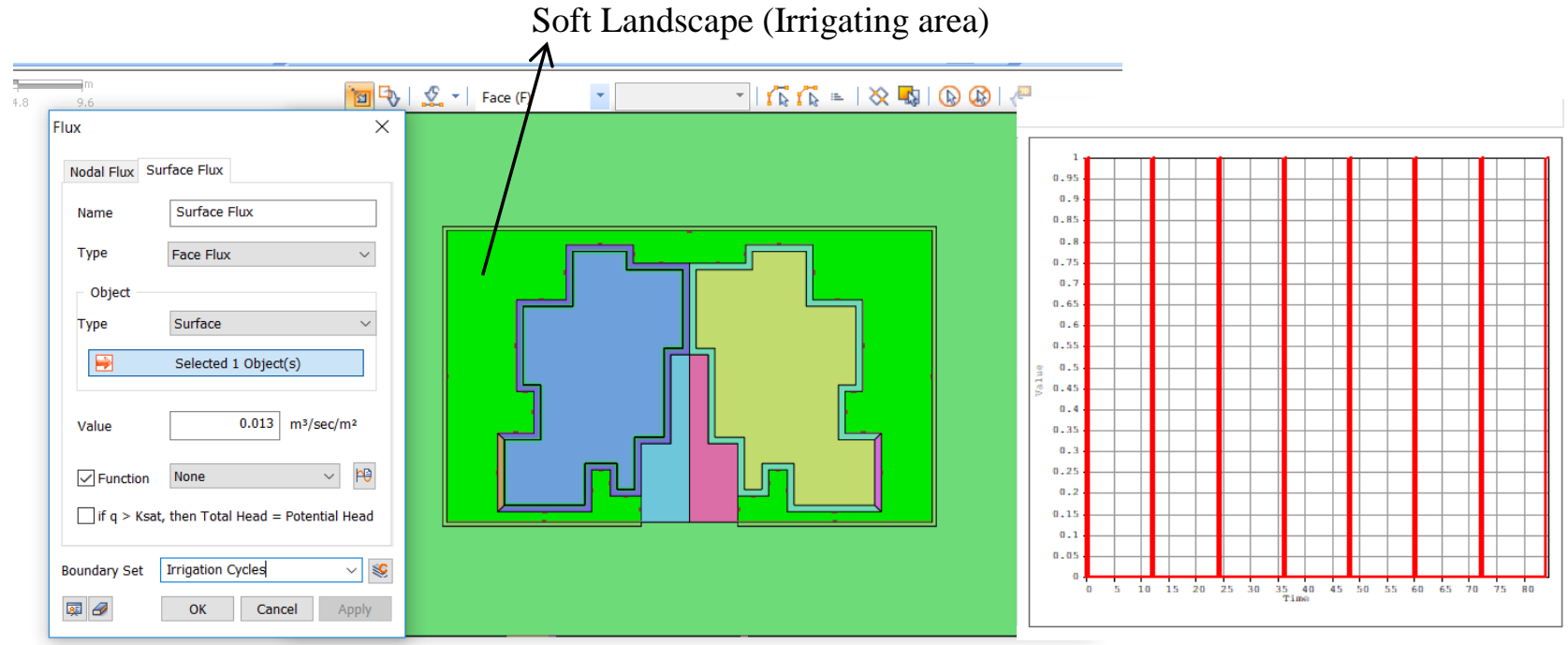

8 Seepage boundary conditions of the model (mesh un-selected for clear view) 


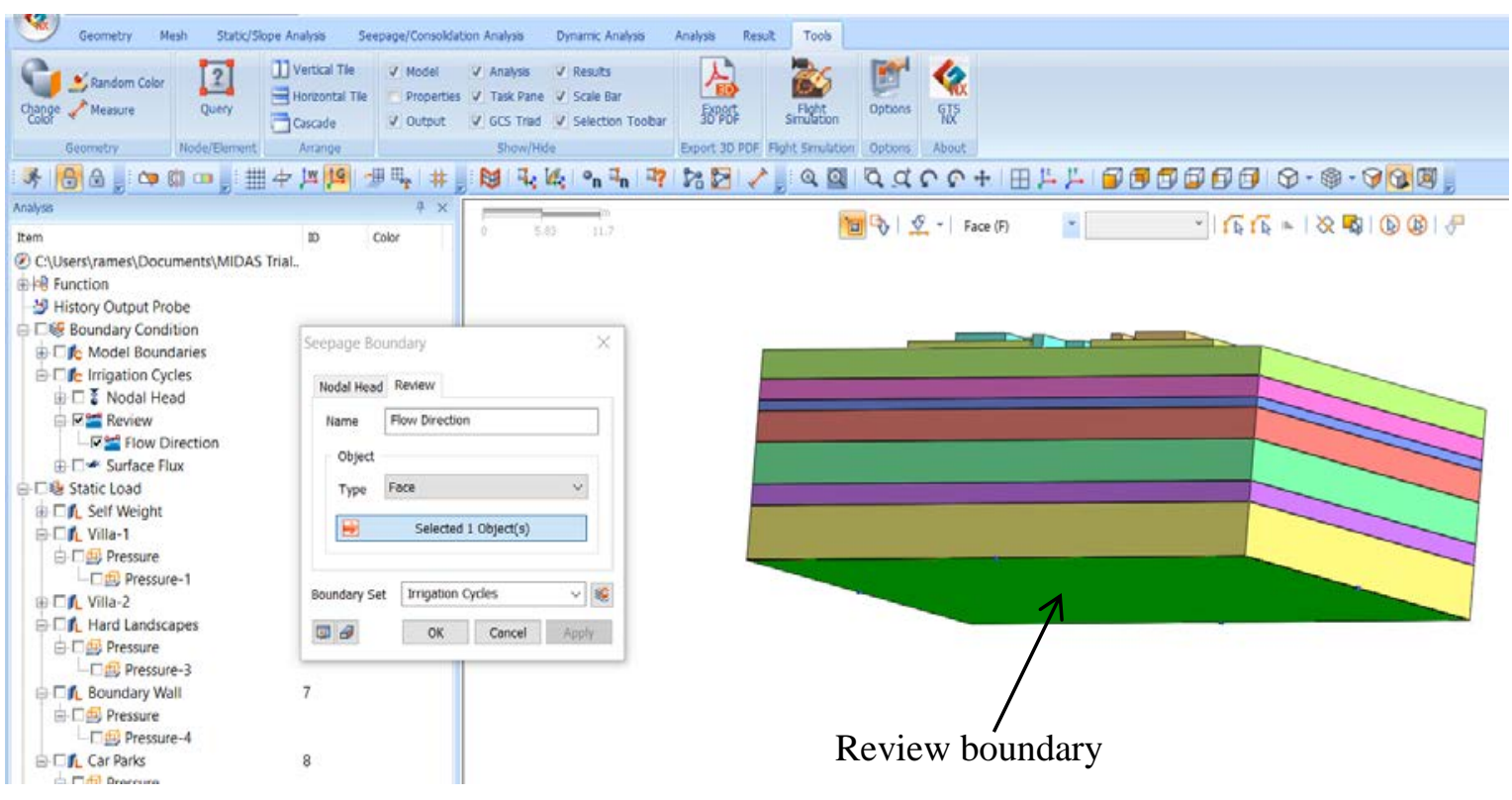

9 Direction simulation of seepage in the model (mesh un-selected for clear view) 


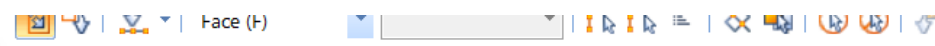
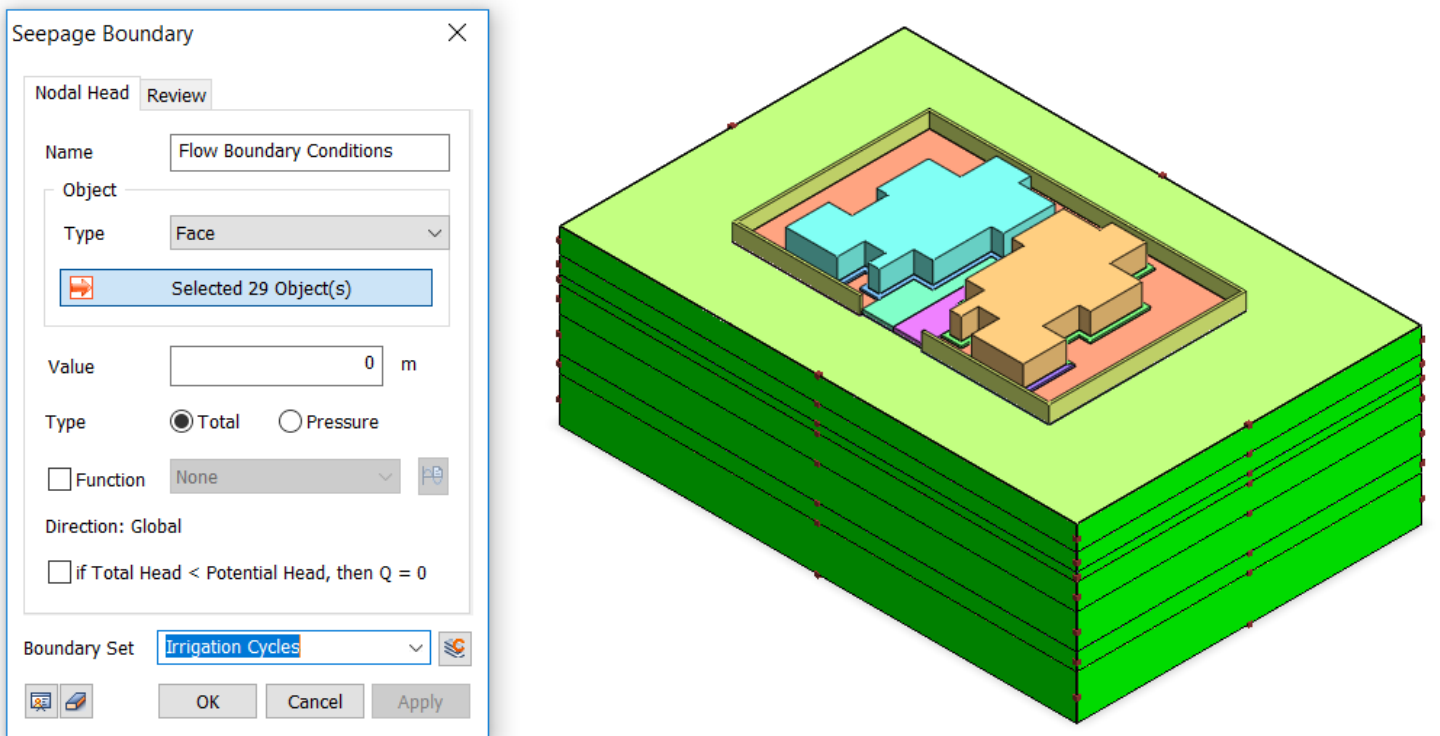

10 Seepage boundary conditions of the model (mesh un-selected for clear view) 


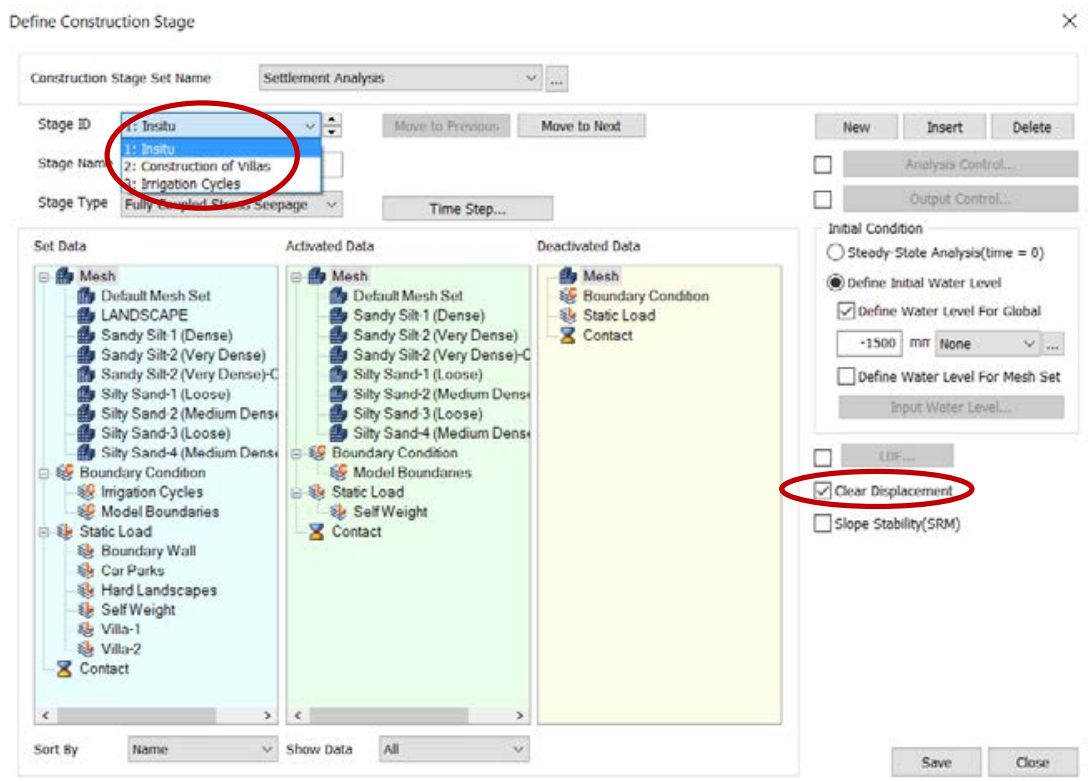

11 Staged construction sequences in the analysis 


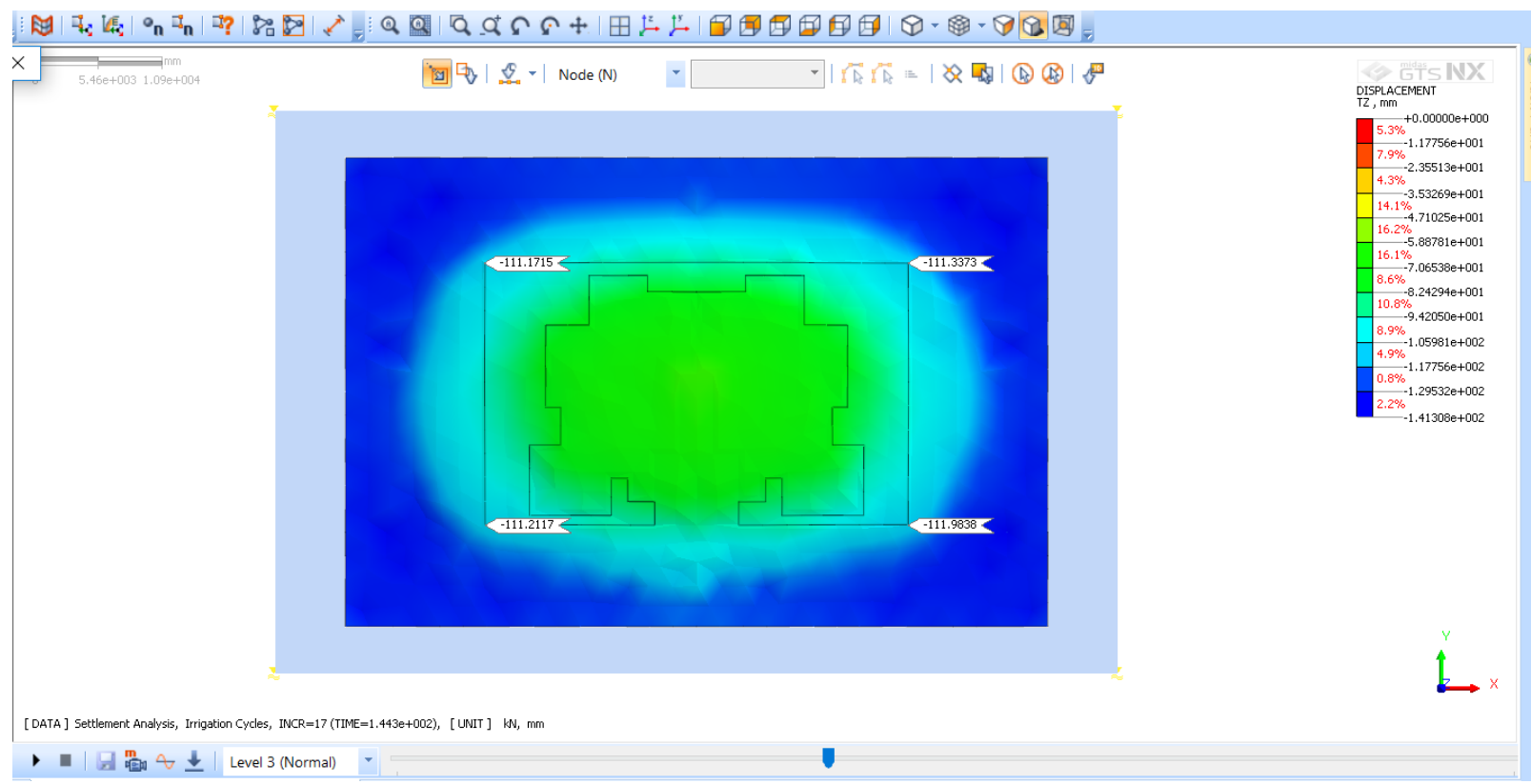

12 Settlement of soil under boundary wall at the end of $17^{\text {th }}$ irrigation cycle with ground water at $1.5 \mathrm{~m}$ depth 


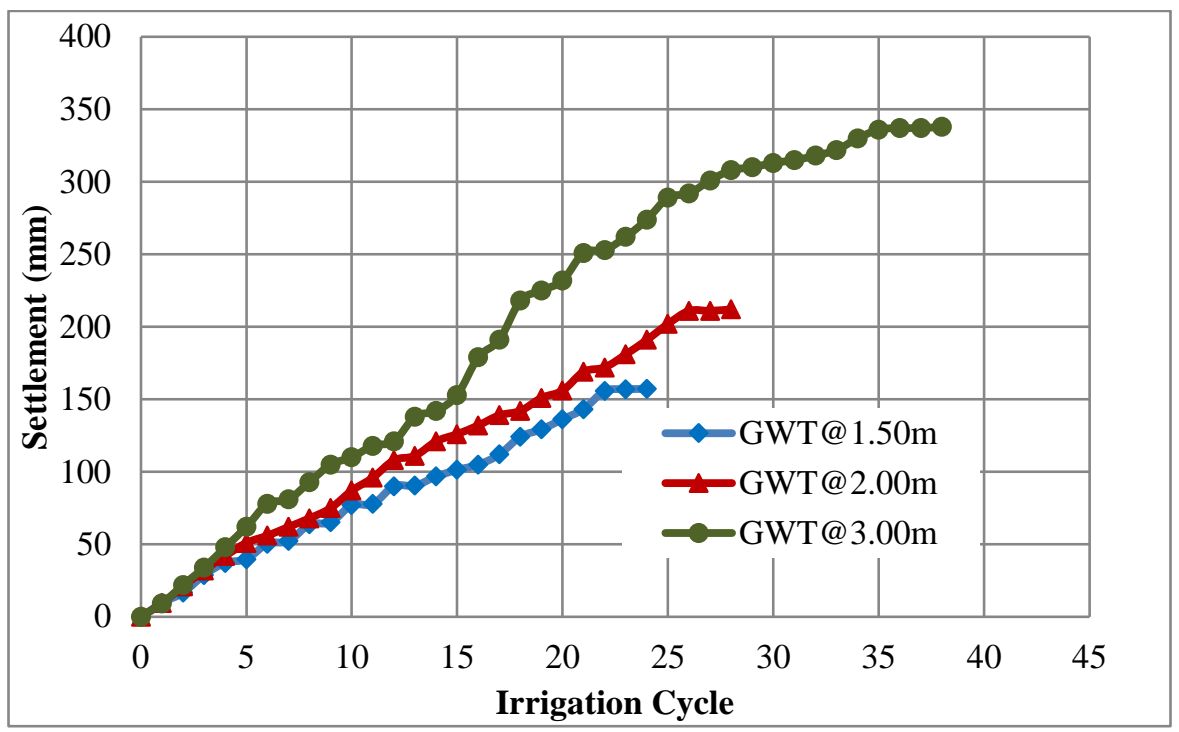

13 Settlement versus irrigation cycles at various depths of groundwater table 


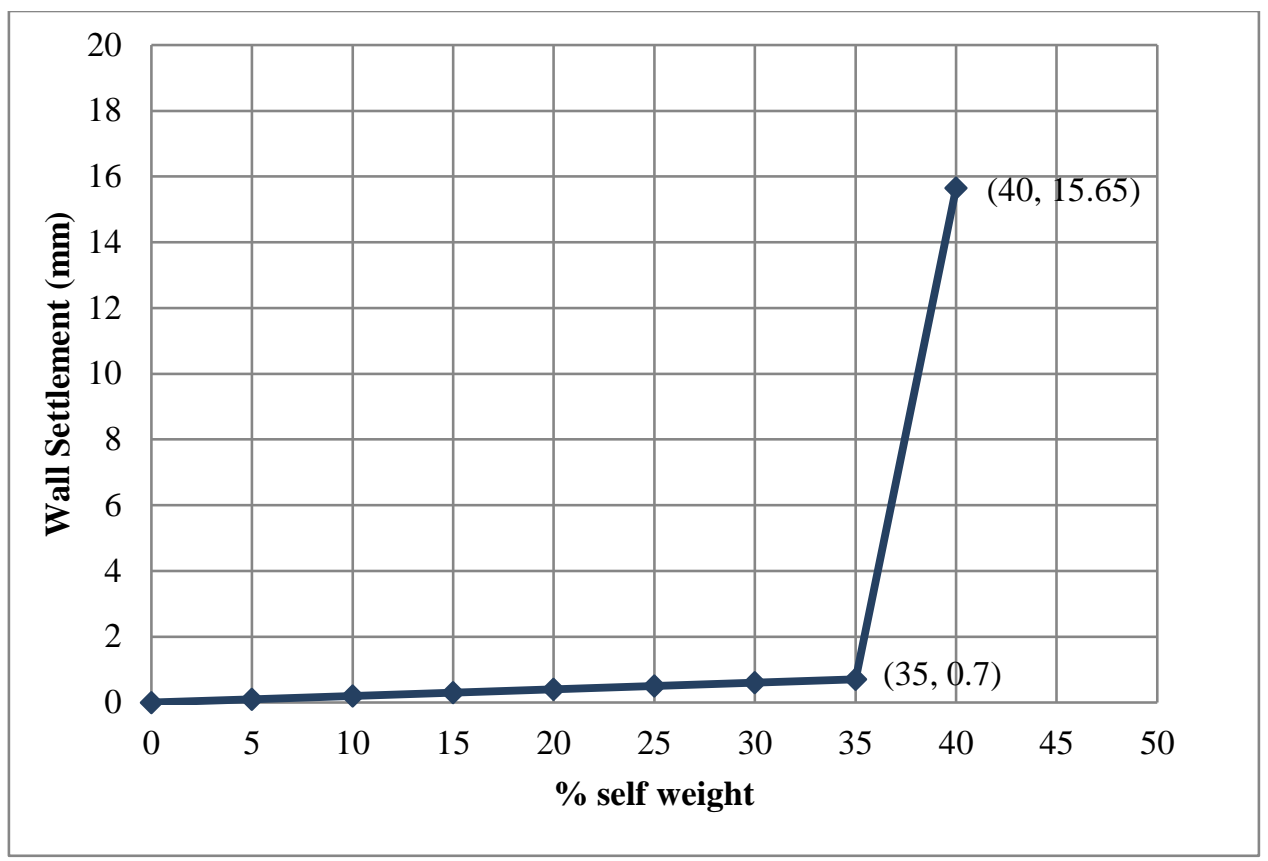

14 Wall settlements at various percentage of self-weights 


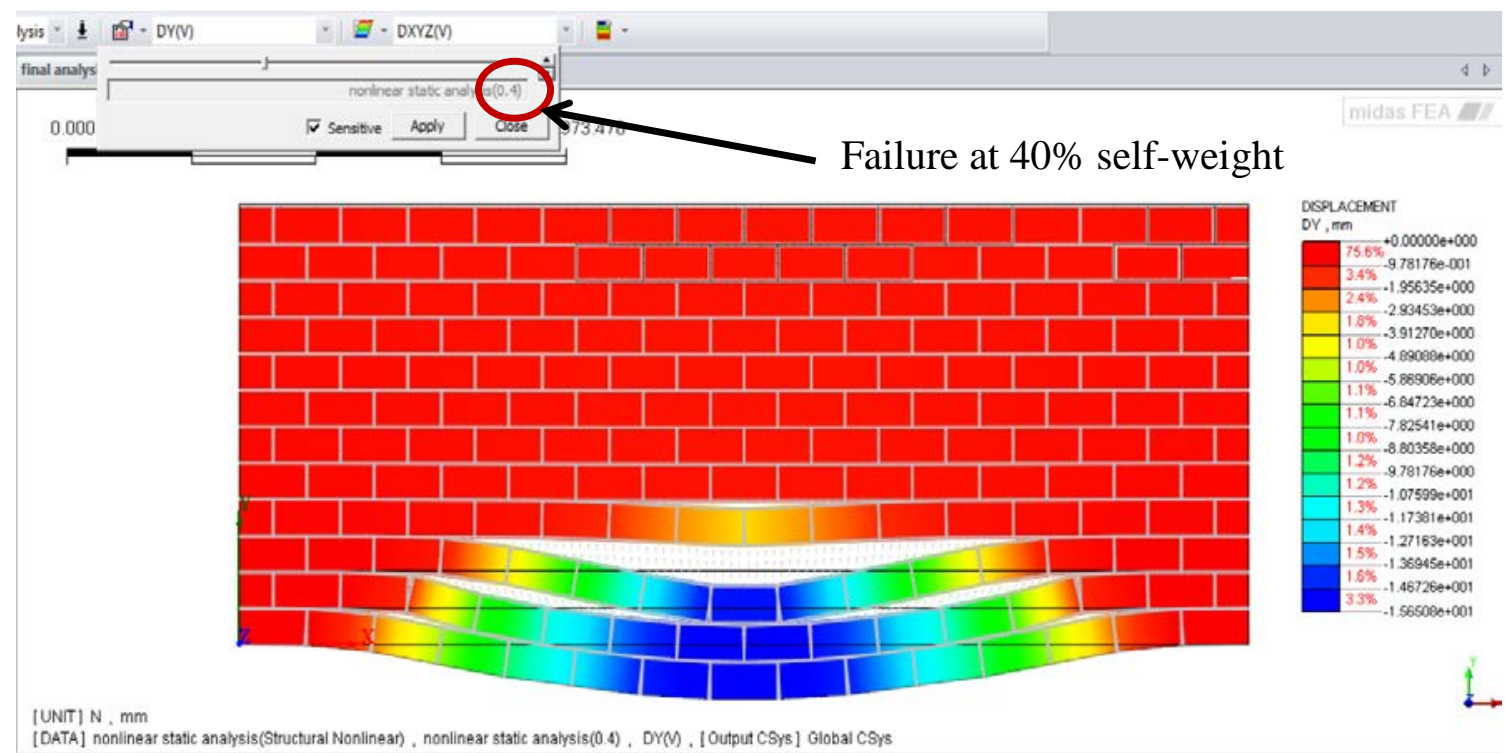

15 Failure pattern of wall at $40 \%$ self-weight 
Table 1 General stratification profile of the case study site

\begin{tabular}{cccc}
\hline Depth $(\mathbf{m})$ & Description of Soil & $\begin{array}{c}\text { Range of } \\
\text { SPT values }\end{array}$ & Relative Density \\
\hline $0.0-3.0$ & Silty SAND & $3-15$ & Very loose to medium dense \\
\hline $3.0-5.0$ & Silty SAND & $14-27$ & Medium dense \\
\hline $5.0-6.0$ & Silty SAND & $6-30$ & Loose to medium dense \\
\hline $6.0-9.0$ & Silty SAND & $13-24$ & Medium dense \\
\hline $9.0-13.0$ & Sandy SILT & $16-50$ & Very dense \\
\hline $13.0-15.0$ & Sandy SILT & $>50$ & \\
\hline
\end{tabular}


Table 2 Input soil parameters in the analysis

Geotechnical parameters from lab tests / correlations

\begin{tabular}{cccccc} 
Depth $(\mathrm{m})$ & $\begin{array}{c}\text { Dry } \\
\text { Density } \\
\left(\mathbf{k N} / \mathbf{m}^{3}\right)\end{array}$ & $\begin{array}{c}\text { Friction } \\
\text { Angle } \\
(\mathbf{d e g r e e s})\end{array}$ & $\begin{array}{c}\text { Initial } \\
\text { Void } \\
\text { Ratio }\end{array}$ & $\begin{array}{c}\text { Elastic } \\
\text { Modulus } \\
\left(\mathbf{k N} / \mathbf{m}^{2}\right)\end{array}$ & $\begin{array}{c}\text { Permeability } \\
(\mathbf{m} / \mathbf{s})\end{array}$ \\
\hline $0.0-3.0$ & 14.00 & 30 & 0.89 & 5000 & $8.00 \times 10^{-5}$ \\
\hline $3.0-5.0$ & 17.00 & 34 & 0.56 & 16000 & $3.00 \times 10^{-5}$ \\
\hline $5.0-6.0$ & 14.67 & 31 & 0.81 & 8000 & $6.00 \times 10^{-5}$ \\
\hline $6.0-9.0$ & 16.50 & 33 & 0.61 & 15000 & $5.00 \times 10^{-5}$ \\
\hline $9.0-13.0$ & 17.60 & 35 & 0.51 & 18000 & $8.00 \times 10^{-6}$ \\
\hline $13.0-15.0$ & 20.00 & 38 & 0.33 & 20000 & $4.00 \times 10^{-6}$ \\
\hline
\end{tabular}


Table 3 Input parameters for the soil-structure interaction analysis of the boundary wall

\begin{tabular}{|c|c|c|c|}
\hline Material & Parameter & Unit & Value/Description \\
\hline \multirow{4}{*}{ Brick } & Material & - & Cement concrete \\
\hline & Size (length $\mathrm{x}$ height $\mathrm{x}$ width) & $\mathrm{mm}$ & $400 \times 200 \times 200$ \\
\hline & Elastic modulus & $\mathrm{N} / \mathrm{mm}^{2}$ & 16700 \\
\hline & Weight density & $\mathrm{kN} / \mathrm{m}^{3}$ & 21.6 \\
\hline \multirow{4}{*}{ Mortar } & Material & - & Cement mortar (1:6) \\
\hline & Compressive strength & $\mathrm{N} / \mathrm{mm}^{2}$ & 7.5 \\
\hline & Thickness & $\mathrm{mm}$ & 10 \\
\hline & Tensile strength & $\mathrm{N} / \mathrm{mm}^{2}$ & 0.15 \\
\hline \multirow{2}{*}{$\begin{array}{l}\text { Interface } \\
\text { properties }\end{array}$} & Normal stiffness modulus & $\mathrm{N} / \mathrm{mm}^{3}$ & 14 \\
\hline & Shear stiffness modulus & $\mathrm{N} / \mathrm{mm}^{3}$ & 62 \\
\hline
\end{tabular}

